expectorated daily. $X$-ray examination revealed cavitation in the left lower lobe-near its upper part posteriorly. Bed rest and general treatment failed to produce any improvement ; indeed, the $x$-ray appearances after three months were, if anything, rather worse (Figs. 10 and 11). Accordingly thoracolysis was advised. On March 31. 1938, under general anaesthesia (intratracheal oxygen and chloroform), the posterior ends of ribs six to ten were resected subperiosteally and their periosteal beds cauterized with Zenker's fluid. The immediate post-operative period was uneventful.

It was recorded in the notes on May 12, 1938, that since operation the patient had done amazingly well: the sputum had decreased from one ounce to three spots daily, and on that day he had had none for the first time for years. $X$-ray examination showed the cavity diminishing in size. A few bacilli were found in one specimen of sputum about the middle of September, after it had been repeatedly negative for about two months.

On October 31, 1938, the general condition was excellent ; a slight but steady increase in weight having taken place since August, the weight now was $10 \mathrm{st} .7 \mathrm{lb}$., and the sputum was so scanty that a specimen obtained with the utmost difficulty was negative. The $x$-ray appearances are correspondingly improved and suggest that healing has occurred (Fig. 12). The patient is now being allowed up, and sputum is negative on culture and animal inoculation.

\section{Case VIII}

An upholsterer aged 25 was admitted to the sanatorium on November 16, 1937, nine weeks after the first onset of his illness, which was regarded as a bronchopneumonia of the right base.

Slight improvement followed routine sanatorium treatment, but in February, 1938, a large basal cavity was seen in the $x$-ray picture of the right lung. Accordingly an artificial pneumothorax was induced, but as this was inadequate it was supplemented on April 6, 1938, by crushing of the right phrenic nerve, and the cavity became a little smaller. On June 30,1938 , there was still a little sputum containing tubercle bacilli, and an occasional slight elevation of temperature to $98.8^{\circ} \mathrm{F}$. The pulse ranged between 75 and 100 per minute and the weight was $9 \mathrm{st} .10 \mathrm{lb}$. The cavity appeared in the $x$-ray picture to have increased (Figs. 15 and 16). Accordingly thoracolysis was advised. On July 7, 1938, under general anaesthesia (intratracheal oxygen and chloroform), posterior portions of ribs six to eleven were resected subperiosteally and their periosteum was cauterized with Zenker's fluid. The immediate post-operative period was marked by an elevation of the temperature, starting some days after the operation and persisting for a few days until the contents of a large haematoma were expelled from the wound during a fit of coughing.

The general condition steadily improved; the sputum, becoming negative, ceased, and $x$-ray examinations showed the cavity to be diminishing (Fig. 17) and then finally to disappear (Fig. 18). Although there was a slight loss of weight immediately after operation, three months later the patient was more than a stone heavier than immediately before it, and he was being allowed up for about four hours daily. The sputum is negative on culture and animal inoculation.

\section{Summary}

Attention is drawn to the possibility of treating successfully certain cases of pulmonary tuberculosis, especially those in which a middle or lower zone of one lung is involved by fibro-cavernous disease, in which an adequate artificial pneumothorax cannot be established, and in which phrenic paralysis fails to effect healing.

The underlying principles of the method and the possibility of extending its scope are referred to, and a series of eight cases in which it was employed with success are recorded.
It is possible, with the operation described and in suitable cases, to obtain healing with the minimum diminution in the functional capacity of the chest and often even with an active diaphragm.

We wish to acknowledge our indebtedness to our colleagues, the medical superintendents and their assistants at the sanatoria -Preston Hall, Ransom, and Wooley-where these cases were treated, for their co-operation in the selection and postoperative management of these, as well as for their interest in the problems involved and help in providing access to their records. We are similarly grateful to Dr. Philip Ayre and Dr. J. K. Hasler for their skilled administration of the anaesthetics required in these cases.

\section{REFERENCES}

Maurer, A., Tobé, F., and Davy, P. E. (1935). Rev. Tuberc., 5 ser., 1,904 and Rautureau, R. (1936). Ibid., 5 ser., 2, 642.

Monaldi, V. (1934). Atti mem. Soc. Lombardia Chir., 11, Seduta del 25 Novémbre.

\section{CRITICAL REVIEW OF EXTRAPLEURAL PNEUMOTHORAX}

BY

\section{R. NISSEN, M.D.}

Professor of Surgery in the University of Istanbul

In 1929-at first without knowledge of the case treated by Meyer fifteen years previously-I used extrapleural pneumothorax for a considerable number of patients, and have since reported thereon (Nissen, 1931, 1932, 1933, and 1937). Numerous publications during the last two years, personal communications from surgeons and tuberculosis doctors, and my own observations while visiting clinics and sanatoria show that extrapleural pneumothorax has become a very frequently used method. I was the first to reintroduce this treatment, and now, after nine years' experience of it, think that a stand should be made against the present tendency to extend the indications for its use. I will not go into these in detail now, but will first discuss the disadvantages and complications of extrapleural pneumothorax. The operation is an adventure into the unknown - to a lesser extent the same objection may be raised against the classical artificial pneumothorax, and unexpected complications may disturb the placid course of the medical treatment of phthisis-but, as will be shown, in extrapleural pneumothorax the mechanical conditions created at operation are immediately subject to modifications, for the most part beyond our control.

\section{Its Disadvantages and Complications}

EMPHYSEMA OF THE MEDIASTINUM

One possible complication is that after completion of the operation air escapes as a result of bouts of coughing, causing general emphysema and threatening to involve the mediastinum. In one of my cases a very serious emphysema of the mediastinum occurred the night after the operation, and I believe that only incision into the jugular notch prevented a fatal outcome.

\section{DIFFICULTY IN REFILLING}

When air has escaped from the extrapleural pneumothorax it may be difficult to find the right tissue space again in attempting to refill. It is true that the exudate usually gives the right clue. But everyone with experience of artificial pneumothorax refills realizes how awkward it is to introduce air without knowing just where one is. There is no manometric indication, for after extrapleural pneumothorax the pressure oscillates round about zero. 


\section{HAEMORRHAGE}

A slight haemorrhage is hardly ever absent. Its clinical and prognostic significance is the same as that of an exudate (see below). A big haemorrhage can endanger life simply as a result of the quantity of blood lost. I have seen a patient-it is true with a complete extrapleural pneumothorax - with such a high degree of anaemia that he recovered only with the help of several large blood transfusions. These massive secondary haemorrhages, which occur in about 10 to 15 per cent. of cases, cannot be avoided by careful haemostasis during the operation, either by diathermy coagulation or, as carried out by Churchill in Boston, by silver clips. Most of the secondary haemorrhages arise only some hours or even days after operation. In one of my cases a very large haemorrhage developed the third day after operation. The cause of this late haemorrhage will not be discussed here. The mechanical consequences of haemorrhage can be no less harmful than the biological. Unless the parietal pleura and the fascia endothoracica are firmly adherent, then enlargement of the extrapleural cavity invariably follows. With that, in many cases, the desirable selective action of extrapleural pneumothorax is lost. It is obvious that a haematoma, especially on the right side, may exert unpleasant pressure on the heart. Aspiration of the extravasated blood is in general contraindicated, for this is almost always followed by renewed bleeding.

THE EXUDATE

The exudate in extrapleural is similar to the early exudate in intrapleural pneumothorax: some writers declare it occurs in 100 per cent. of cases, others only in 17 per cent. or even 5 per cent. I have in practice always observed exudate in extrapleural pneumothoraxinsignificant in a very few cases and considerable in the great majority. There is the risk that each exudate, small as well as large, may become infected in the extrapleural cavity, and infections are frequent-considerably more common, for example, than after plombage: it must not be forgotten that occasional infection of the bed of the plombe was one of the chief arguments against plombage.

The outlook of the conservative treatment of empyema in extrapleural pneumothorax is less favourable than it is in intrapleural empyema; this applies equally to septic empyemata as to tuberculous ones. The connective tissue lining of the cavity of the extrapleural pneumothorax has not the resorptive power of the pleura. The picture of septic suppuration-happily rare-resembles in its severity that of the empyema familiar when adhesions were treated with high-pressure pneumothorax. The fulminating inflammation spreads in the extrapleural space (occasionally also to the mediastinum). The prognosis is very bad. In mild forms of suppuration the cavity must be drained when the condition cannot be dealt with by puncture and irrigation. Usually in these cases induration of the connective tissue of the wall of the cavity is favourable to its healing. A voluminous fibrothorax is formed. The proliferating connective tissue also envelops the cavity wall and prevents its re-expansion. I will refer later to the therapeutic significance of fibrothorax in extrapleural pneumothorax.

If the drained abscess cavity does not close spontaneously, then it must be treated in the same way as a persisting cavity in an intrapleural empyema: first an extrapleural thoracoplasty is done ; later, if necessary, this is followed by an intrapleural (Schede's) operation. It may be difficult to decide on the right moment to do a thoracoplasty: there is a tendency to wait too long-until the patient, exhausted by the suppuration, is unable to stand the operation. Also, the technical procedure needed to obliterate the space demands much surgical experience ; occasionally it is necessary to fill with muscle the cavity which has remained in spite of rib resection.

One can thus see that the operative treatment of the complications of extrapleural pneumothorax demands essentially more general surgical knowledge than the performance of the initial operation. Extrapleural pneumothorax can be carried out with little technical equipment and little technical experience and ability. The longwinded literary expositions of individual tuberculosis surgeons who busy themselves with operative tactics give, it is true, the opposite impression.

\section{PERFORATION OF CAVITY}

As with each pneumolysis, so also in extrapleural pneumothorax there is the obvious risk that careless or clumsy manipulation may rupture a peripheral cavity which has already broken into the inner layer of the chest wall. Suture of the tear is generally not possible ; even if this can be done it usually separates after twentyfour to forty-eight hours. Tamponage has no effect on the catastrophic outcome. Only active permanent collapse by means of extrapleural thoracoplasty (apicolysis) with subsequent tamponage of the tear in the collapsed cavity will be successful.

It is otherwise with the late perforation of cavities which have been compressed by extrapleural pneumothorax. This is seldom acute; it more often develops gradually, and it is then usually difficult to determine whether an already existing suppuration in the extrapleural cavity has prepared the way for the rupture or whether, rather, septic infection of the extrapleural pneumothorax is the result of perforation of a cavity. Once it is certain that there is a perforation the thoracoplasty which has been described must be carried out immediately if the strength of the patient permits this. We were able to restore two patients in this way. It is noteworthy that one of these cases perforated in the third month of treatment.

\section{MAINTENANCE OF EXTRAPLEURAL PNEUMOTHORAX}

Even if none of the previously described complications arises-that is, if a more or less dry cavity exists-it can in no way be assured that regular refills will maintain the cavity at the required size. In this connexion we must be clear that connective tissue and not endothelium lines the cavity. The opposite view, held by Schmidt, is erroneous. Macroscopically the lining of the cavity does indeed give the impression of a smooth endothelium. Observation of the envelope of tissue round a plombe of paraffin made us aware that this conclusion was wrong. In both, one finds on microscopical examination only connective tissue cells as a surface covering.

The tendency to obliteration is very strong. This need not necessarily be clinically disadvantageous. I have already referred to the favourable action of a fibrothorax, which takes the place of the extrapleural pneumothorax. We can also sometimes observe this massive formation of connective tissue in an extrapleural pneumothorax which is aseptic and free, or almost free, of exudate. Fibrosis obtains in spite of all attempts at refilling; the cavity disappears, sometimes after four months and sometimes considerably later (nine months). One should, however, only discontinue these attempts when the clinical picture and $x$-ray examination clearly show the development of a compact fibrothorax, with disappearance of the cavity. Otherwise, as soon as it is confirmed that obliteration of 
the cavity has begun, the air must be replaced by oil. This "anti-symphysis" oleothorax sometimes works, preventing the further shrinking in of the cavity. If it does not, then one must try to establish collapse by means of thoracoplasty.

\section{Conclusions}

Extrapleural pneumothorax is an "easy" operation for both doctor and patient. But this statement must be qualified by pointing out that a variety of complications are possible. The "optimistic" literature at present available is based on but brief experience. Having had nine years' experience, I believe that much greater caution must be urged. Thoracoplasty and its various modifications and plombage are superior to extrapleural pneumothorax. When it is possible to apply them, extrapleural pneumothorax should not be thought of. It should only be considered when pneumothorax fails as a result of widespread adhesion, when the extent of this does not allow of plombage, or when the general condition or the state of the other lung does not permit of a thoracoplasty. That was approximately the conclusion I reached in my first publication in 1931, and after many digressions I have now returned to it. Within these narrow indications extrapleural pneumothorax is the only possible method of collapse therapy. It may be employed even though one cannot expect much from it. But the rare permanent results gain in value when one considers the hopeless fate of the patients for whom this form of therapy is recommended.

A doubtful indication is in recent cavities with delicate pleural adhesions, where a thoracoplasty seems unsuitable on account of the risk of mediastinal flutter, and a plombe because of the likelihood of its slipping down. These cases are relatively rare. We now perform extrapleural pneumothorax for them only so long as we can assume a sufficient degree of pleural thickening. Then we replace it by thoracoplasty (apical thoracoplasty). Extrapleural pneumothorax here plays the part of a preparation for rib resection.

\section{REFERENCES}

Nissen, R. (1931). Ther d. Gegenw. 72, 433, 497. (1932). Uेber die neuere Entwicklung der chirurgischen Behandlung der Lungentuberkulose, Urban and Schwarzenberg, Berlin.

(1933). Med. Klinik, 29, 767

(1937). Schweiz. med. Wschr., 67, 334

The following medical promotions in and appointments to the Venerable Order of the Hospital of St. John of Jerusalem were announced in the London Gazette of January 3: as Knight, Dr. L. W. Dryland; as Commanders, Dr. A. G. Osborn (since deceased), Colonel G. C. E. Simpson, O.B.E., T.D., Hon. W. H. Kauntze, C.M.G., M.B.E., M.D., Dr. A. G. S. Broughton, Lieutenant-Colonel W. Blackwood, D.S.O., Captain F. H. R. Heath ; as Officers, Dr. J. A. Carman, Dr. J. A. Kennedy, Dr. H. M. Palmer, Dr. D. E. Brown, M.B.E., Lieutenant-Colonel W. R. Stewart, C.I.E., I.M.S., Colonel H. Stott, O.B.E., I.M.S., Colonel W. Archibald, Dr. F. W. M. Palmer, Colonel C. H. S. Redmond, T.D., A.M.S., Lieutenant-Colonel F. W. W. Dawson, Dr. R. Y. Stones, O.B.E., M.C., Dr. J. B. Mitchell, O.B.E., Captain D. C. Low, Lieutenant-Colonel G. C. Lawson, Dr. Sybil C. Bevan; as Serving Brothers, Dr. W. F. J. Whitley, Dr. C. R. Corfield, Dr. R. W. Jubb, Captain R. P. Cormack, Dr. Francis Liddell, Dr. W. B. Grant, Dr. W. Wood, Dr. J. A. Hendry, Dr. J. B. Aickin, Dr. S. M. Vassallo, Dr. D. G. Hunter ; as Associate Serving Brother, Mr. D. D. Variava, O.B.E.; as Serving Sisters, Dr. Alice M. Benham, Dr. Gladys E. Wilkinson, Dr. Mildred M. E. Y. Edwards.

\section{ANAESTHESIA IN THORACIC SURGERY}

BY

\section{J. T. HUNTER, M.R.C.S., L.R.C.P.}

Anaesthetist to the Brompton Hospital, and the Prince of Wales's Hospital, Tottenham

In no other branch of surgery is the anaesthetist faced with such difficulties as in thoracic operations: each operation presents one or more problems that are found in these cases alone. The procedures are not only extensive, but they take a long time and cause a good deal of haemorrhage and shock. Added to these features is the everpresent question of the correct method of dealing with a case that has sputum in any quantity.

Beyond the technical difficulties, there is the fact that the surgeon is practically always operating on a patient with a disease of long standing and of a nature which causes a degree of toxic absorption.

\section{Preparation of Patient}

Generally speaking, the preparation of the patient is just the same as for any other operation of any magnitude. Rest, increased fluids, and glucose, with attention to oral hygiene and the intestinal tract, are essential, and should be carried out as thoroughly as possible, provided the patient will not suffer by any delay. Where there is any sputum a course of postural drainage is invaluable in reducing the quantity at the time of operation, and in the intrapleural operations an artificial pneumothorax is necessary on the affected side, and should be induced some three or four days before operation. Premedication should be of the lightest. Perhaps the most useful combination is omnopon 1/3 grain and scopolamine $1 / 150$ grain, given three-quarters of an hour before operation. No drug should be used that will diminish the cough reflex to any extent. Basal narcosis may suit nervous patients, but drugs of transient action that are quickly and easily detoxicated should be employed. Evipan and sodium pentothal are the most useful in this group, and of the two sodium pentothal is probably the better. Though avertin is an excellent basal narcotic, its action is prolonged, and where a quick return to consciousness is desirable, as in these cases, it is to be avoided.

\section{Local Anaesthesia}

This is used extensively on the Continent, but comparatively rarely in the British Isles. The infiltration of the area to be operated on is carried out with different preparations of novocain in varying strengths, but where an experienced anaesthetist is available there is no doubt that other methods are preferable. Infiltration takes a long time and needs multiple skin punctures. Surgeons in this country seem to prefer, where major operations are concerned, to operate on an unconscious patient-and, moreover, the average British patient would rather be unconscious of the operation if it is to take any length of time. A number of operations can, however, be carried out easily and successfully by this method. These will be classified later.

\section{Spinal Analgesia}

High spinal analgesia has proved excellent in lobectomy and thoracoplasty. One of the first papers on this subject was published by Shields (1935) of Toronto, and it 